\title{
Evidence based optimization of medical therapy in Chronic Heart Failure
}

\author{
Nilufar Fatema1, Rakash Sharma², Phillip Poole Wilson³, Colin Galloway ${ }^{4}$. \\ ${ }^{1}$ Department of Cardiology, Bangabandhu Sheikh Mujib Medical University, Dhaka \\ ${ }^{2}$ Department of Cardiology, Royal Brompton hospital, London \\ ${ }^{3}$ Department of Cardiology, National Heart \& Lung Institute, London \\ ${ }^{4}$ Department of Cardiology, Royal Brompton hospital, London, UK \\ Address of correspondence \\ Dr. Nilufar Fatema, Consultant, Department of Cardiology, University cardiac centre, Banga Bandhu Sheikh Mujib Medical University, \\ Shahbag, Dhaka \\ Email address: drnilufar@hotmail.com
}

\begin{abstract}
Despite of modern medical treatment heart failure patients suffer frequently. The optimization of medical therapy is an emphasis for these patients. Device therapy has been showed some improvement in prognosis but nonresponder rate is still $30 \%$ in many large trails. So, selection of patients for devices is important as these are expensive. Optimization of medical treatment is the priority and device can be used as an additional option.
\end{abstract}

\section{Introduction}

Heart failure is a chronic debilitating disease. Symptomatic improvement has been achieved with pharmacological treatment e.g. use of beta blockers, angiotensin-converting enzyme inhibitors and diuretics. Although the medical management of chronic heart failure patients has improved considerably over recent times, morbidity and mortality remain high and quality of life is poor for many patients.

Chronic heart failure has significant economic impact on health budgets due to the cost of long-term drug treatment and frequent hospitalization of patients. Heart failure will be an increasing burden in the future due to the recent development of health care systems, advanced treatment. ${ }^{1-2}$, With an aging population the prevalence of heart failure is increasing. ${ }^{3}$ Modern treatments have improved the prognosis of heart failure. ${ }^{4}$

Currently, the beneficial role of an electromechanical approach (pace maker) has been promoted as an effective adjunct therapy to optimum medical therapy in selected heart failure patients but not as an alternative.

The purpose of this review is to evaluate the role of optimum pharmacological therapy in chronic heart failure patients.

\section{Definition of Heart Failure}

It is a difficult to establish a uniform definition of heart failure due to many concepts from different bodies. It differs dependent on epidemiology, clinical finding and treatment. A recent European definition which is mostly accepted by different authorities is as follows: 'Heart failure is a complex syndrome that can result from any structural or functional cardiac disorder that impairs the ability of the heart to function as a pump to support a physiological circulation'.5

\section{Prevalence and Incidence of Chronic Heart failure}

In Europe, the prevalence of heart failure is approximately $1-3 \%$ of the population. The incidence rate is 1 case per 1,000 of population per year. ${ }^{6}$ The prevalence in USA is about 5 million people and more than 550,000 new patients are diagnosed to have heart failure each year. ${ }^{7}$ The Framingham Heart Study reported no change in the period 1950-1999 for men, but a small fall in the early stage of that period for women. ${ }^{8}$ In the developing countries, about $2 \%$ of the adult population have heart failure. ${ }^{9}$

\section{Current trends of treatment of heart failure}

In the United Kingdom, community management may be carried out by special technology-telemonitoring; called'Home Care link', by which remote monitoring of heart failure patients is possible. The first sign of clinical deterioration of the patient is noticed by telemonitoring nurse and then the nurse refers the patient to primary care doctor. The Meta analysis found that telemonitoring programmes for patients with chronic heart failure reduced admissions to hospital, improved quality of life and all cause mortality by nearly one fifth. ${ }^{10}$

\section{Classification of Heart failure}

1) Acute, 2) Chronic, and 3) Decompensated.

\section{European Society of Cardiology (ESC) described a new classification in 2008}

1. New onset- First presentation of heart failure which is acute or slow onset.

2. Transient- Recurrent or episodic.

3. Chronic- Persistent, stable, worsening or decompensated. 


\section{Managements of Chronic Heart Failure}

In clinical practice heart failure is diagnosed by history, clinical features and investigations.

\section{General measures}

1) Weight reduction, 2) Cessation of smoking, 3) Stop alcohol intake, 4) Diet restriction: Salt restriction :It is important to restrict salt intake as it promotes heart failure, 5) Fluid restriction: Fluid intake will be restricted in 1 to $1.5 \mathrm{~L}$ per day but it will vary with weather, 6) Exercise, 7) Risk factor management: Patients who have risk factors for the development of the premature coronary artery disease then it lead to heart failure. So control of risk factors is important. Such as, cessation of smoking, weight reduction, control of diabetes, hypertension and hyperlipidemia. It has been shown in recent trail that statin reduces mortality in chronic heart failure patients due to any cause. ${ }^{11}$

\section{Pharmacological treatment}

The main aim of pharmacological treatment is to control the symptoms and improve prognosis.

\section{Diuretics}

It is the main stay of treatment of acute heart failure. There is no evidence that diuretics affect the prognosis or survival rate of patients with chronic heart failure. But the chronic heart failure patients respond well and get symptomatic relieves to loop diuretics (like frusemide, bumetanide) as well as thiazides or potassium-sparing diuretics: Aldosterone antagonists or amiloride etc.

\section{Beta blocker}

Following table demonstrates different trials of beta blockers in heart failure patients:

Table 3: The doses of beta blockers in different trials.

\begin{tabular}{|l|l|l|l|c|l|}
\hline Drug & $\begin{array}{c}\text { Initial } \\
\text { dose(mg) }\end{array}$ & $\begin{array}{c}\text { Titration } \\
\text { steps(mg) }\end{array}$ & $\begin{array}{c}\text { Target } \\
\text { dose(mg) }\end{array}$ & $\begin{array}{c}\text { Freque- } \\
\text { ncy }\end{array}$ & Trial \\
\hline Carvedilol & 3.125 & $6.25,12.5,25,50$ & $25 / 50$ & b.d & COPERNICUS \\
\hline Bisoprolol & 1.25 & $2.5,5,10$ & 10 & o.d & CIBIS-II \\
\hline Metoprolol & $12.5 / 25$ & $25,50,100,200$ & 200 & o.d & MERIT-HF \\
\hline Nebivolol & 1.25 & $2.5,5,10$ & 10 & o.d & SENIORS \\
\hline
\end{tabular}

Many clinical trials have demonstrated that beta blockers have significantly reduced mortality in chronic heart failure patients. ${ }^{12}$ Carvedilol was used in severely symptomatic chronic heart failure patient in another trial and showed mortality benefit. ${ }^{13}$ It also reduces the risk of sudden cardiac death which have been shown in MERIT-HF and CIBIS-II studies. ${ }^{14,15}$. Some physicians are reluctant to start beta blocker as it has potential side effects like worsening of heart failure, hypotension and bradycardia. ${ }^{15}$

\section{ACE inhibitors}

Several studies have been shown the importance of ACE inhibitor in the prognosis of heart failure patients, such as enalapril was used in both CONSENSUS trial, SOLVD trial. ${ }^{16,17 .}$

Table 4: The doses of Angiotensin converting enzyme inhibitors in different trials.

\begin{tabular}{|l|l|l|c|c|l|}
\hline Drug & $\begin{array}{c}\text { Initial } \\
\text { dose }(\mathrm{mg})\end{array}$ & $\begin{array}{c}\text { Titration } \\
\text { steps(mg) }\end{array}$ & $\begin{array}{c}\text { Target } \\
\text { dose(mg) }\end{array}$ & $\begin{array}{c}\text { Freque- } \\
\text { ncy }\end{array}$ & Trial \\
\hline Captopril & 6.25 & $12.5,25,50$ & 50 & t.d.s. & SAVE \\
\hline Enalapril & 2.5 & $5,10,20$ & 20 & b.d. & SOLVD \\
\hline Lisinopril & 5 & $10,20,30,40$ & $35-40$ & o.d. & ATLAS \\
\hline Ramipril & 2.5 & 5,10 & 10 & o.d. & HOPE \\
\hline Trandolopril & 0.5 & $1,2,4$ & 4 & o.d. & TRACE \\
\hline
\end{tabular}

\section{Angiotensin-II receptor blockers}

The CHARM trial has shown that Cardesartan has a beneficial effect on prognosis, as it reduces both mortality and morbidity. ${ }^{18}$ Cohn et al. used Valsartan in their trial which showed improvement of quality of life in chronic heart failure patients. ${ }^{19}$

\section{Aldosterone inhibitors}

Spironolactone has been shown survival benefit in chronic heart failure patients in one large placebo- controlled study: RALES Trial. The risk of death was 30\% lower in Spironolactone group than the placebo $(\mathrm{P}<0.001) .{ }^{20}$

\section{Vasodilators}

Mortality benefit has been shown in a trial in the treatment of chronic heart failure with hydralazine and isosorbide dinitrate. ${ }^{21,22 .}$

\section{Calcium-channel blockers}

There is no evidence in extra survival benefit of Calciumchannel blocker in heart failure.

\section{Positive inotropic agents}

Digitalis is used in chronic heart failure patients with atrial fibrillation for rate control.

There is evidence that it reduces symptoms but has no effect on mortality. ${ }^{23}$ Other positive inotropic agents (such as dobutamine, dopamine, and milrinone) are used in patients for short period for their clinical improvement. 


\section{Anticoagulation}

Anticoagulation is also an important consideration as chronic heart failure patients with atrial fibrillation have risk of systemic embolism. Anticoagulation therapy reduces the incidence of embolism. ${ }^{24}$

\section{Antiarrhythmic agents}

Amiodarone is the drug of choice to maintain sinus rhythm in patients with heart failure and atrial fibrillation. Sotalol is also used.

\section{Device therapy}

\section{Cardiac resynchronization therapy (CRT)}

If patients with advanced heart failure that is NYHA class III and IV who are in optimal medical treatment, have a broad QRS duration $>120 \mathrm{~ms}$ or left bundle branch block with myocardial dysfunction ( $\mathrm{EF}<35 \%$ ) may be suitable for cardiac resynchronization therapy (CRT). ${ }^{5}$ CRT has been shown to reduce hospital admission and mortality in comparison with conventional treatment. 25 . But nonresponder rate to CRT was $30 \%$ in this trial.

\section{Implantable cardioverter-defibrillator (ICD)}

Fatal ventricular arrhythmia is the common cause of sudden cardiac death in chronic heart failure patients.

The UK guidelines laid down by the National Institute of Clinical Excellence (NICE) relating to patients with sustained ventricular tachycardia advice implanting a defibrillator in two groups of patients. ${ }^{5}$ In one group patients presenting with haemodynamically compromising VT causing collapse, hypotension, left ventricular failure or angina. And the other group was patients presenting with sustained VT without the above features but with an ejection fraction $<$ $35 \%$.

\section{Left ventricular assist device (L-VAD)}

Ventricular assist devices were implanted as bride to recovery, bride to transplant and destination therapy in 107 patients with end stage heart failure. The data suggested that Post-VAD survival rate has significantly improved. ${ }^{26}$ About $52 \%$ of survival improvement has been demonstrated in a trial with young patients with rapidly failing hearts with LVAD. 27

\section{Cost of heart failure}

Approximately $2 \%$ of total health budget has been spent on heart failure patients in United Kingdom. $5 \%$ of acute hospital admissions and 10\% bed occupancy and $40 \%$ readmission rate in one year. As chronic heart failure is a chronic disease so long term drug therapy is a burden for health budget. 6

\section{Prognosis}

About 50\% mortality in 3 years which is worse than cancer. ${ }^{\mathrm{s}}$ Median survival after diagnosis is 1.7 years for men and 3.2 years for women. The risk of sudden death is 10 times higher in heart failure patients.

\section{Quality of life questionnaire}

The 'Minnesota Living with Heart Failure Questionnaire' is used to assess the prognosis of patients with heart failure. This is used commonly in most trials.

The 'Karolinska Questionnaire' is also used in a trial 'MUSTIC' which measures all broad spectrum of quality of life.

\section{Conclusions}

The prevalence of heart failure is increasing. Despite improvement of pharmacological therapy some heart failure patients present to the physician repeatedly for their symptoms and poor quality of life. Optimization of pharmacological therapy may be helpful for some heart failure patients. Many trials have shown that CRT reduces morbidity and mortality in certain refractory heart failure patients.

\section{References}

1. Armstrong, P. W. \& Moe, G. W. "Medical advances in the treatment of congestive heart failure", Circulation,1993; 88 (6): 2941-52.

2. Baker, D. W., Jones, R., Hodges, J., Massie, B. M., Konstam, M. A., \& Rose, E. A. "Management of heart failure. III. The role of revascularization in the treatment of patients with moderate or severe left ventricular systolic dysfunction", JAMA, 1994; 272 (19): 1528-34.

3. Bonneux, L., Barendregt, J. J., Meeter, K., Bonsel, G. J., \& van der Maas, P. J. "Estimating clinical morbidity due to ischemic heart disease and congestive heart failure: the future rise of heart failure", Am.J.Public Health, 1994; 84 (1): $20-8$.

4. Clark, A. L. \& Coats, A. J. "New evidence for improved survival in chronic heart failure", Clin.Cardiol.,1994; 17 (2): $55-8$.

5. NICE Guidelines. Developed by The National Collaborating Centre for Chronic Conditions. Chronic Heart Failure. National clinical guidelines for diagnosis and management in primary and secondary care NICE guideline No.5.1-163. London,Royal College of Physicians. 2005; Ref Type: Generic

6. Cowie, M. R., Mosterd, A., Wood, D. A., Deckers, J. W., Poole-Wilson, P. A., Sutton, G. C., \& Grobbee, D. E. "The epidemiology of heart failure", European Heart Journal, 1997; 18: 208-25.

7. Thom, T., Haase, N., Rosamond, W., Howard, V. J., Rumsfeld, J., Manolio, T., Zheng, Z. J., Flegal, K., O'Donnell, 
C., Kittner, S., Lloyd-Jones, D., Goff, D. C., Jr., Hong, Y., Adams, R., Friday, G., Furie, K., Gorelick, P., Kissela, B., Marler, J., Meigs, J., Roger, V., Sidney, S., Sorlie, P., Steinberger, J., Wasserthiel-Smoller, S., Wilson, M., \& Wolf, P. "Heart disease and stroke statistics--2006 update: a report from the American Heart Association Statistics Committee and Stroke Statistics Subcommittee", Circulation, 2006; 113 (6): 85-151.

8. Levy, D., Kenchaiah, S., Larson, M. G., Benjamin, E. J., Kupka, M. J., Ho, K. K., Murabito, J. M., \& Vasan, R. S. "Long-term trends in the incidence of and survival with heart failure", N Engl J Med, 2002; 347: 1397-402.

9. Mendez, G. F. \& Cowie, M. R. "The epidemiological features of heart failure in developing countries: a review of the literature", Int.J Cardiol, 2001; 80: 213-9.

10. Clark, R. A., Inglis, S. C., McAlister, F. A., Cleland, J. G., \& Stewart, S. "Telemonitoring or structured telephone support programmes for patients with chronic heart failure: systematic review and meta-analysis", BMJ, 2007; 334 (7600): 942.

11. Folkeringa, R. J., Van Kraaij, D. J., Tieleman, R. G., Nieman, F. H., Pinto, Y. M., \& Crijns, H. J. "Statins associated with reduced mortality in patients admitted for congestive heart failure", J.Card Fail., 2006; 12 (2): 134-8.

12. Shibata, M. C., Flather, M. D., \& Wang, D. "Systematic review of the impact of beta blockers on mortality and hospital admissions in heart failure", Eur.J Heart Fail., 2001; 3: 351-7.

13. Packer, M., Coats, A. J., Fowler, M. B., Katus, H. A., Krum, H., Mohacsi, P., Rouleau, J. L., Tendera, M., Castaigne, A., Roecker, E. B., Schultz, M. K., \& DeMets, D. L. "Effect of carvedilol on survival in severe chronic heart failure", $N$ Engl J Med, 2001; 344: 1651-8.

14. CIBIS-II Investigator "The Cardiac Insufficiency Bisoprolol Study II (CIBIS-II): a randomised trial", Lancet, 1999; 353: 9-13.

15. Wikstrand, J., Hjalmarson, A., Waagstein, F., Fagerberg, B., Goldstein, S., Kjekshus, J., \& Wedel, H. "Dose of metoprolol CR/XL and clinical outcomes in patients with heart failure: analysis of the experience in metoprolol CR/XL randomized intervention trial in chronic heart failure (MERIT-HF)", J.Am.Coll.Cardiol.2002; 40 (3): 491-8.

16. The CONSENSUS Trial Study Group "Effects of enalapril on mortality in severe congestive heart failure. Results of the Cooperative North Scandinavian Enalapril Survival Study (CONSENSUS). The CONSENSUS Trial Study Group", New England Journal of Medicine, 1987; 316:1429-35.

17. The SOLVD investigators "Effect of enalapril on survival in patients with reduced left ventricular ejection fractions and congestive heart failure", New England Journal of Medicine, 1999; 325: 293-302.
18. Granger, C. B., McMurray, J. J., Yusuf, S., Held, P., Michelson, E. L., Olofsson, B., Ostergren, J., Pfeffer, M. A., \& Swedberg, K. "Effects of candesartan in patients with chronic heart failure and reduced left-ventricular systolic function intolerant to angiotensin-converting-enzyme inhibitors: the CHARM-Alternative trial", Lancet, 2003; 362: 772-6.

19. Cohn, J. N. \& Tognoni, G. "A randomized trial of the angiotensin-receptor blocker valsartan in chronic heart failure", N Engl J Med, 2001; 345: 1667-75.

20. Pitt, B., Zannad, F., Remme, W. J., Cody, R., Castaigne, A., Perez, A., Palensky, J., \& Wittes, J. "The effect of spironolactone on morbidity and mortality in patients with severe heart failure. Randomized Aldactone Evaluation Study Investigators [see comments]", N Engl J Med, 1999; 341: 709-17.

21. Cohn, J. N., Archibald, D. G., Ziesche, S., Franciosa, J. A., Harston, W. E., Tristani, F. E., Dunkman, W. B., Jacobs, W., Francis, G. S., Flohr, K. H., Goldman, S., Cobb, F. R., Shah, P. M., Saunders, R., Fletcher, R. D., Loeb, H. S., Hughes, V. C., \& Baker, B. "Effect of vasodilator therapy on mortality in chronic congestive heart failure. Results of a Veterans Administration Cooperative Study", New England Journal of Medicine, 1986; 314: 1547-52.

22. Taylor, A. L., Ziesche, S., Yancy, C., Carson, P., D'Agostino, R., Jr., Ferdinand, K., Taylor, M., Adams, K., Sabolinski, M., Worcel, M., \& Cohn, J. N. "Combination of isosorbide dinitrate and hydralazine in blacks with heart failure", N.Engl.J.Med. 2004; 351 (20): 2049-57.

23. The Digitalis Investigation Group "The effect of digoxin on mortality and morbidity in patients with heart failure", New England Journal of Medicine, 1997; 336: 525-33.

24. Remme, W. J. \& Swedberg, K. "Guidelines for the diagnosis and treatment of chronic heart failure", Eur.Heart J, 2001; 22: 1527-60.

25. Cleland, J. G., Daubert, J. C., Erdmann, E., Freemantle, N., Gras, D., Kappenberger, L., \& Tavazzi, L. "The effect of cardiac resynchronization on morbidity and mortality in heart failure", New England Journal of Medicine, 2005; 352: 1539-49.

26. Osaki, S., Edwards, N. M., Velez, M., Johnson, M. R., Murray, M. A., Hoffmann, J. A., \& Kohmoto, T. "Improved survival in patients with ventricular assist device therapy: the University of Wisconsin experience", Eur.J.Cardiothorac. Surg. 2008; 34 (2): 281-8.

27. Sharples, L., Buxton, M., Caine, N., Cafferty, F., Demiris, N., Dyer, M., \& Freeman, C. "Evaluation of the ventricular assist device programme in the UK", Health Technol.Assess., 2006; 10 (48): 1-IV. 